\title{
Use of interactive teaching -Learning approaches in anatomy
}

\author{
Swapna B Parate ${ }^{1 *}$, Prashant A. Bhusari ${ }^{2}$, Vaishali S Anturlikar ${ }^{3}$ \\ ${ }^{1}$ Associate Professor, ${ }^{2}$ Professor and HOD, ${ }^{3}$ Assistant Professor, Dept. of Anatomy, SMBT IMS \& RC, Nashik, Maharashtra, \\ India
}

*Corresponding Author: Swapna B Parate

Email: drswapna.sorte@gmail.com

\begin{abstract}
Introduction: Understanding of anatomy is fundamental for clinical practice; Anatomy must be taught and learnt within a context that is clinically meaningful and related to the competencies required by new medical graduates so that students understand its relevance to their future practice. Hence in this study we decided to implement interactive clinical anatomy lecture.
\end{abstract}

Aim: To assess the impact of the interactive teaching learning methods on student cognitive outcomes and to evaluate the perceptions of students about interactive teaching learning approach.

Materials and Methods: Faculty members were sensitized. The study was approved by institutional Ethics Committee. Written informed consent was taken from students. The anatomy knowledge was evaluated by a pre-test and post-test (10 MCQ), which were designed based on the learning objectives of the sessions. Student's perception was evaluated through prevalidated questionnaires. The topic was chosen for interactive sessions namely "Venous drainage of lower limb" and we were including video clips and demonstration of Trendelenburg test in this session. Students had learned this topic already during didactic lecture as a part of routine timetable.

The pre-test and post-test results of the study group were compared using 'paired t' test. Students feedback was determined by analysis of questionnaires based on 5 point Likert scale.

Results: Total participants were 150. The mean score of pretest and posttest were 3.7 and 4.2 respectively. Standard deviation for pretest and posttest were 1.52 and 1.51 respectively. $t$ value of this study was 7.99 and $\mathrm{P}$ value was 0.0000 . Here $\mathrm{P}$ value is less than 0.001 , it shows the highly significant difference between the mean of pretest and posttest score. It indicates definite improvement in the knowledge of students. In the prevalidated feedback questionnaires, $64.7 \%$ students had agreed that session was better than didactic lecture and $82.7 \%$ students had agreed that it was more effective in fulfilling learning objective. $70.7 \%$ students wanted the need to conduct more such sessions on the other topics also. All faculties agreed that this method increases student interest in learning and better understand clinical aspects of anatomy. However faculties believed that this method requires planning, extra effort, infrastructure and also some training.

Discussion: Introducing clinical knowledge in interactive teaching is beneficial in assessment also, it can lead to improvement in anatomy scores. Educational research has shown that students who are actively involved in the learning activity will learn more than students who are passive recipients. Learning and its retention is facilitated when the subject matter of the topic is linked to authentic contexts since the students experience the essentiality of knowing the topic for future clinical practice.

Conclusion: This study determined that the interactive and engaging learning strategy can be used as an effective learning tool in anatomy. So there was not only significant improvement in anatomy knowledge with its applied aspects but also it helps to improve students communication.

Keywords: Interactive teaching learning in Anatomy, Clinical Anatomy.

To assess the impact of the interactive teaching learning methods on student cognitive outcomes and to evaluate the perceptions of students about interactive teaching learning approach. The anatomy knowledge was evaluated by a pre-test and post-test. Student's perception was evaluated through prevalidated questionnaires. The topic was chosen for interactive sessions namely "Venous drainage of lower limb" and we were including video clips and demonstration of Trendelenburg test on the patient in classroom setting. Students had learned this topic already during didactic lecture as a part of routine timetable.

The pre-test and post-test results of the study group were compared using 'paired t' test. Students 
feedback was determined by analysis of questionnaires based on 5 point Likert scale.

The mean score of pretest and posttest were 3.7 and 4.2 respectively. Standard deviation for pretest and posttest were 1.52 and 1.51 respectively. $t$ value of this study was 7.99 and $P$ value is less than 0.001 . In the prevalidated feedback questionnaires, $64.7 \%$ students had agreed that session was better than didactic lecture and $82.7 \%$ students had agreed that it was more effective in fulfilling learning objective. $70.7 \%$ students wanted the need to conduct more such sessions on the other topics also. All faculties agreed that this method increases student interest in learning and better understand clinical aspects of anatomy.

This study determined that the interactive and engaging learning strategy can be used as an effective learning tool in anatomy. So there was not only significant improvement in anatomy knowledge with its applied aspects but also it helps to improve students communication.

\section{Introduction}

The transition from undergraduate to first year medical education can be difficult for students because of the dramatic increase in the volume of content. Anatomy is usually considered to be the 'foundation of medical sciences' ${ }^{1-3}$ but it is also perceived to be an onerous and challenging subject in medical education. ${ }^{4}$ Although an understanding of anatomy is fundamental for clinical encounters and professional practice. ${ }^{2,5}$ Furthermore, anatomists face the recent pressures of the changing modes of medical education and assessment, with fewer contact hours and limited resources to teach an extremely diverse group of students with different sets of prior scientific literary levels, cultural backgrounds and experiences. ${ }^{6,7} \mathrm{New}$ strategies are emerging in anatomy teaching that incorporate technology, making learning interactive, student-centered and more appealing to general student body. ${ }^{8-10}$ Bonwell and Eison defined active learning as "anything that involves students in doing things and thinking about the things they are doing", ${ }^{11}$ and Felder and Brent mentioned active learning as "anything course-related that all students in a class sessions are called upon to do other than simply watching, listening and taking notes". ${ }^{12}$ Anatomy must be taught and learnt within a context that is clinically meaningful and related to the competencies required by new medical graduates so that students understand its relevance to their future practice. Competent clinicians, particularly surgeons, need a deep understanding of anatomy for safe clinical procedures. However, because students have had very limited exposure to anatomy during clinical training, there is a concern that medical students are ill prepared in anatomy when entering their internship and residency programs. Therefore, developing effective modalities for teaching anatomy is essential to safe medical practice.

Hence in this study we decided to implement interactive clinical anatomy lecture. This helps in recognition of the relevance of the subjects taught in the class room, thus making the learning "contextual."

\section{Aim and Objectives}

1. To assess the impact of the interactive teachinglearning methods on student cognitive outcomes.

2. To evaluate the perceptions of Students about interactive teaching- learning approach.

\section{Materials and Methods}

Faculty members were sensitized. The study was approved by Institutional Ethics Committee. The objectives of the study were explained to first year MBBS students. Written informed consent was taken from student $(n=150)$ who were willing to participate in the study. The anatomy knowledge was evaluated by a pre-test and post-test (10 MCQ), which were designed based on the learning objectives of the sessions. Student's perception was evaluated through prevalidated questionnaires. The topic was chosen for interactive session namely "Venous drainage of lower limb" and we were including video clips and demonstration of Trendelenburg test on the patient in this session. Students had learned this topic already during didactic lecture as a part of routine timetable.

\section{Statistical analysis}

The pre-test and post-test results of the study group were compared using 'paired t' test. Student's feedback was determined by analysis of questionnaires based on 5 point likert scale. 


\section{Results}

Table 1: The pre-test and post-test results of the study were compared using 'paired t' test.

\begin{tabular}{|l|l|l|}
\hline & Pre-test score & Post-test score \\
\hline Mean & 3.7 & 4.2 \\
\hline SD & 1.52 & 1.51 \\
\hline ' $t$ ' value 7.99 & \\
\hline P value $<\mathbf{0 . 0 0 1}$ & \\
\hline
\end{tabular}

Here $\mathrm{P}$ value $<0.001$ shows the highly significant difference between the mean of pre-test and post-test score. It indicates definite improvement in the knowledge of students.

Table 2: Students perception about interactive teaching-learning session questionnaires in percentage (\%)

\begin{tabular}{|l|c|c|c|c|c|}
\hline Questionnaires & \multicolumn{3}{l|}{ Percentage of student's Responses } \\
\cline { 2 - 5 } & SA & A & N & D & SD \\
\hline Session was better than didactic lectures & 20 & 54.7 & 17.3 & 6 & 2 \\
\hline Session motivates me to learn more in subject & 18.7 & 50 & 12 & 11.3 & 8 \\
\hline Session was more effective in fulfilling learning objective & 32 & 50.7 & 4 & 7.3 & 6 \\
\hline Session helps me to comprehend better in discussion & 25.3 & 40 & 12.7 & 15.3 & 6.7 \\
\hline Session improves my communication skill & 21.3 & 41.3 & 20 & 9.3 & 8 \\
\hline Session promotes understanding of basics rather than memorization & 37.3 & 52 & 4 & 4 & 2.7 \\
\hline Session provides an opportunity to apply knowledge to different clinical cases & 34.7 & 45.3 & 10 & 8 & 2 \\
\hline Session definitely helps to improves my diagnostic skill & 25.3 & 34.7 & 12 & 24.7 & 3.3 \\
\hline Session was well organized & 29.3 & 45.3 & 14.7 & 6.7 & 4 \\
\hline Session was enjoyable & 22.7 & 24 & 17.3 & 21.3 & 14.7 \\
\hline Need to conduct more such sessions on the other topics & 24 & 46.7 & 21.3 & 5.3 & 2.7 \\
\hline Session discussion facilitates interaction between faculty and students & 27.3 & 50.7 & 14.7 & 4 & 3.3 \\
\hline
\end{tabular}

Likert's Scale- Strongly Agree (SA), Agree (A), Neutral (N), Disagree (D), Strongly Disagree (SD).

In the prevalidated feedback questionnaires, $74.7 \%$ students had agreed that session was better than didactic lecture and $82.7 \%$ students had agreed that it was more effective in fulfilling learning objective. $70.7 \%$ students wanted the need to conduct more such sessions on the other topics also.

\section{Faculty Perception}

All faculties agreed that this method increases student interest in learning and they better understand clinical aspects of anatomy. However faculties believed that this method requires planning, extra effort, infrastructure and also some training.

\section{Discussion}

The present study demonstrated that students found the interactive learning strategy beneficial. It helped them to use and apply knowledge in a constructive, active and interesting way. Moreover; students achieved significantly better scores in post-test. Interactive teaching enriches and contextualize that learning and offers a wider variety of teaching and learning methods. Introducing clinical knowledge in interactive teaching is beneficial in assessment also, it can lead to improvement in anatomy scores. ${ }^{13}$ Spencer $\mathrm{J}$ et al found direct contact with patients can be seen to play a crucial role in the development of clinical reasoning, communication skills, professional attitudes and empathy. ${ }^{14}$

Educational research has shown that students who are actively involved in the learning activity will learn more than students who are passive recipients. ${ }^{15}$ Learning and its retention is facilitated when the subject matter of the topic is linked to authentic contexts since the students experience the essentiality of knowing the topic for future clinical practice. ${ }^{16}$

The goals of medical education should be student oriented in which the student development should be 
along with knowledge, skills and attitude. Learning is the active process going on inside the student's mind and teachers main role is to facilitate this learning process. $^{17}$ A good learning involves a good communication. ${ }^{18}$

\section{Conclusion}

This study determined that the interactive and engaging learning strategy can be used as an effective learning tool in anatomy. So there was not only significant improvement in anatomy knowledge with its applied aspects but also it helps to improve students communication. Though the use of this method requires planning and commitment to the teaching process, the result of this learning are productive.

\section{Source of funding}

None.

\section{Conflict of interest}

None.

\section{References}

1. Pujol S, Baldwin M, Nassiri J, Kikinis R, Shaffer K. Using 3D Modelling techniques to enhance teaching of difficult anatomical concepts. Acad Radiol 2016;23(4):507-16.

2. Tubbs RS, Sorenson EP, Sharma A, Benninger B, Norton N, Loukas M, Moxham BJ. The development of a core syllabus for the teaching of head and neck anatomy to medical students. Clin Anat 2014;27:321-30.

3. Guimaraes B, Durado L, Tsisar S, Diniz JM, Madeira MD, Ferreira MA. Rethinking anatomy: how to overcome challenges of medical Education's evolution. Acta Medica Port 2017;30(2):134-40.

4. Dimon T Jr. Anatomy of the moving body. A basic course in bones, muscles and joints. 2nd Ed. Berkeley, California: North Atlantic Books. 2008. p.280.

5. Smith CF, Finn GM, Stewart J, McHanwell S. Anatomical society core regional anatomy syllabus for undergraduate medicine: the Delphi process. J Anat 2016;228:2-14.

6. Tworek JK, Jamniczky HA, Jacob C, Hallgrímsson B, Wright B. The LINDSAY virtual human project: an immersive approach to anatomy and physiology. Anat Sci Educ 2013;6(1):19-28.
7. Bergman EM. Discussing dissection in anatomy education. Prospect Med Educ 2015;4: 211-3.

8. Kurt E, Yurdakul SE, Atac A. An overview of the technologies used for anatomyeducation in terms of medical history. Procedia Soc Behav Sci 2013;103:109-15.

9. Torres K, Torres A, Pietrzyk L, Lisiecka J, Błoński M, Bącik-Donica M, Staśkiewicz G, Maciejewski R. Simulation techniques in the anatomy curriculum: review of literature. Folia Morphol (Warsz) 2014;73:1):1-6.

10. Waight N, Chiu MM, Whitford M. Factors that influence science teacher's selection and usage of technologies in high school science classrooms. J Sci Educ Technol 2014;23:668-81.

11. Bonwell CC, Eison JAAL. Creating excitement in the classroom. 1991. ASHE-ERIC higher education reports: School of Education and Human Development, the George Washington University; Washington DC: ERIC clearinghouse on. High Educ. 2008:121.

12. Felder RM, Brent R. Active learning: an introduction. ASQ Higher Educ Brief. 2009;2:4-9.

13. Joseph Dusseau, MD; Doug Knutson, MD; David Way, Med. Anatomy Correlations: Introducing Clinical Skills to Improve Performance in Anatomy. Fam Med 2008;40(9):633-72.

14. Spencer J, Blackmore D, Heard S, McCrorie P, McHaffie D, Scherpbier A, Gupta TS, Singh K, Southgate L. Patientoriented learning: a review of the role of the patient in the education of medical students. Med Educ 2000;34(10):8517 .

15. Mrunal R Shenwai. Interactive interventions for enhanced active learning in first MBBS students. Int J Healthcare Biomed Res 2013;2(1):8-11.

16. Kireeti AS, Reddy DS. Case based learning (CBL), a better option to traditional teaching for undergraduate students in curriculum of Paediatrics. Asian J Biomed Pharm Sci 2015;5(45):39-41.

17. Tayade MC, Kulkarni NB. The Interface of Technology and Medical Education in India: Current Trends. Indian J Basic Appl Med Res 2011:(1):8-12

18. Hitesh Mishra, Vipin Kumar, Pankaj Kumar Modi. Comparison of different teaching methodologies in a Medical college in North India. Indian J Basic Appl Med Res 2013;6(2):464-9

19. P. S. Bhuiyan, N. N. Rege, A. N. Supe. The art of Teaching Medical Students, $3^{\text {rd }}$ edition.

How to cite this article: Parate SB, Bhusari PA, Anturlikar VS. Use of interactive teaching -Learning approaches in anatomy. Indian J Anat Surg Head Neck Brain 2019;5(3):76-9.. 